\title{
Recognitional Specificity and Evolution in the Tomato-Cladosporium fulvum Pathosystem
}

\author{
B. B. H. Wulff, ${ }^{1}$ A. Chakrabarti, ${ }^{2,3}$ and D. A. Jones ${ }^{2}$ \\ ${ }^{1}$ Institut de Biologie Moléculaire des Plantes (IBMP-CNRS), 12 rue du Général Zimmer, 67084 Strasbourg, France; \\ ${ }^{2}$ Research School of Biology, The Australian National University, Canberra ACT 0200, Australia; ${ }^{3}$ CSIRO Plant Industry, \\ GPO Box 1600, Canberra ACT 2601, Australia
}

Submitted 18 June 2009. Accepted 16 July 2009.

The interactions between plants and many biotrophic or hemibiotrophic pathogens are controlled by receptor proteins in the host and effector proteins delivered by the pathogen. Pathogen effectors facilitate pathogen growth through the suppression of host defenses and the manipulation of host metabolism, but recognition of a pathogeneffector protein by a host receptor enables the host to activate a suite of defense mechanisms that limit pathogen growth. In the tomato (Lycopersicon esculentum syn. Solanum lycopersicum)-Cladosporium fulvum (leaf mold fungus syn. Passalora fulva) pathosystem, the host receptors are plasma membrane-anchored, leucine-rich repeat, receptor-like proteins encoded by an array of $C f$ genes conferring resistance to $C$. fulvum. The pathogen effectors are mostly small, secreted, cysteine-rich, but otherwise largely dissimilar, extracellular proteins encoded by an array of avirulence (Avr) genes, so called because of their ability to trigger resistance and limit pathogen growth when the corresponding $C f$ gene is present in tomato. A number of $C f$ and $A v r$ genes have been isolated, and details of the complex molecular interplay between tomato Cf proteins and $C$. fulvum effector proteins are beginning to emerge. Each effector appears to have a different role; probably most bind or modify different host proteins, but at least one has a passive role masking the pathogen. It is, therefore, not surprising that each effector is probably detected in a distinct and specific manner, some by direct binding, others as complexes with host proteins, and others via their modification of host proteins. The two papers accompanying this review contribute further to our understanding of the molecular specificity underlying effector perception by $\mathrm{Cf}$ proteins. This review, therefore, focuses on our current understanding of recognitional specificity in the tomato-C. fulvum pathosystem and highlights some of the critical questions that remain to be addressed. It also addresses the evolutionary causes and consequences of this specificity.

Brande Wulff and David Jones contributed equally to this review.

Corresponding author: Brande Wulff and David Jones;

E-mail: Brande-Wulff@ibmp-ulp.u-strasbg.fr and david.jones@anu.edu.au

*The e-Xtra logo stands for "electronic extra" and indicates that additional materials and methods and two supplementary figures are published online.

\section{THE MOLECULAR BASIS FOR RECOGNITIONAL SPECIFICITY IN THE TOMATO-C. FULVUM PATHOSYSTEM}

\section{The Cf-2-Rcr3-Avr2 interaction.}

Recognition of the C. fulvum Avr2 effector protein by the tomato Cf- 2 resistance protein is mediated by the tomato Rcr3 protein (Table 1; Fig. 1). Rcr3 is a secreted cysteine protease required for Cf-2-dependent resistance (Krüger et al. 2002), and Avr2 is a cysteine protease inhibitor that binds and inhibits Rcr3 (Rooney et al. 2005). Avr2 also binds Pip1, a secreted cysteine protease closely related to Rcr3 (Shabab et al. 2008; Tian et al. 2007; van Esse et al. 2008). In this interaction, Cf-2 is thought to recognize the Rcr3:Avr2 complex, but this has not been shown experimentally. Domain swapping experiments between Cf- 2 and Cf-5 (a homolog of Cf-2) have shown that the recognitional specificity of Cf-2 lies between leucine-rich repeat (LRR)3 and LRR27, a region that differs from Cf- 5 by six extra LRR and 78 aminoacid substitutions (Seear and Dixon 2003). Although crudely defined, this region of recognitional specificity corresponds to those in Cf-4, Cf-9, and Cf-9B responsible for recognition of their cognate ligands (Chakrabarti et al. 2009; van der Hoorn et al. 2001a; Wulff et al. 2001, 2009). An additional unanswered question about recognition in this interaction is whether Cf-2 interacts with Rcr3 in the absence of Avr2 or only when Avr2 is bound to Rcr3. It is conceivable that Rcr3 acts as a negative regulator of Cf- 2 activation in the absence of Avr2 and as a positive regulator in the presence of Avr2. Although this question has not been addressed explicitly, there are two pieces of information that address this question indirectly. Unlike Rcr3 from Lycopersicon pimpinellifolium (the source of $C f-2$ ), $\mathrm{Rcr} 3$ from L. esculentum triggers Avr2independent necrosis in mature plants carrying $C f-2$ (Krüger et al. 2002). This indicates that a variant Rcr3 might interact with $\mathrm{Cf}-2$ in the absence of Avr2 but does not necessarily imply that the coadapted Rcr3 does so. It is conceivable that the variant amino acids in $\mathrm{Rcr}{ }^{\text {esc }}$ mimic the effect of Avr2 binding. However, the observation that $\mathrm{Rcr} 3^{\mathrm{pim}}$ is dominant to $\mathrm{Rcr}^{\text {esc }}$ (Dixon et al. 2000; Krüger et al. 2002) is difficult to explain if Rcr3 $3^{\text {esc }}$ is able to interact with Cf-2 but Rcr $3^{\text {pim }}$ does not, unless the level of Rcr $3^{\text {esc }}$ expression in the homozygote is postulated to be above a threshold for Cf-2-dependent cell death and that in the heterozygote to be below. The mature onset of necrosis in Cf-2 Rcr ${ }^{\text {esc }}$ tomato plants associated with increased expression of Rcr3 (Krüger et al. 2002) provides indirect evidence that the $\mathrm{Cf}-2-\mathrm{Rcr} 3^{\text {esc }}$ interaction 
is, indeed, near a threshold for activation. On the other hand, the observation that $R c r 3^{\text {pim }}$ is dominant to $R c r 3^{\text {esc }}$ is easy to explain if Rcr3 $3^{\text {esc }}$ and Rcr3 $3^{\text {pim }}$ are both able to interact with Cf- 2 and Rcr $3^{\text {pim }}$ outcompetes Rcr $3^{\text {esc }}$ for $\mathrm{Cf}-2$ binding and so represses $\mathrm{Cf}-2$ activation in the heterozygote. However, the absence of necrosis in Rcr3-defective mutants carrying $C f-2$ (Dixon et al. 2000; Krüger et al. 2002) argues against Rcr3 acting as a repressor unless Rcr3 is also required to prime $\mathrm{Cf}-2$ ready for activation.

Avr2 and the cysteine protease inhibitor E64, which binds the catalytic site of cysteine proteases, are competitive inhibitors of Rcr3, indicating that Avr2 binds to the catalytic site of Rcr3 (Rooney et al. 2005). The cysteine protease inhibitors EPIC1 and EPIC2B from Phytophthora infestans also inhibit Rcr3, but neither these nor E64 trigger Cf-2-dependent resistance, indicating that inhibition of cysteine protease activity per se is not the trigger for activation of Cf-2 (Rooney et al. 2005; Song et al. 2009). Comparisons of Rcr3 sequences from species closely related to tomato show that variation between Rcr3 sequences occurs predominantly on one face of the protein, among residues surrounding the substrate-binding groove, and that one of these variant residues affects Avr2 binding (Shabab et al. 2008). Five of the six residues that differentiate Rcr3 ${ }^{\text {esc }}$, able to trigger necrosis in Cf-2 tomato plants, from Rcr $3^{\text {pim }}$, which does not, are also located on this face, providing further weight to the idea that $\mathrm{Rcr} 3^{\text {esc }}$ contains amino-acid differences that mimic the effect of Avr2 binding and that $\mathrm{Cf}-2$ detects an Rcr3:Avr2 complex.

\section{The Cf-9-HABS-Avr9 interaction.}

Despite considerable research effort, no direct interaction has been detected between the tomato Cf-9 resistance protein and the C. fulvum Avr9 effector protein (Luderer et al. 2001). Avr9 is a small cystine-knot protein that is structurally homologous to carboxypeptidase inhibitors and various other cystine-knotted inhibitor proteins (Vervoort et al. 1997). No inhibitory activity or inhibitor target has yet been identified for Avr9, although a high-affinity Avr9 binding site (HABS) has been detected in tomato and other solanaceous plants (Kooman-Gersmann et al. 1996). Again, despite considerable research effort, the HABS has not yet been identified nor is there any clue to its function (van der Hoorn 2001). A systematic mutational analysis of Avr9 has shown that two solvent-exposed hydrophobic residues (F21 and L24) critical for recognition by Cf-9 are located in one loop on the surface of Avr9 and an additional solvent-exposed hydrophobic residue (F10) and a basic residue (R08) important for recognition are located nearby on a second loop (KoomanGersmann et al. 1997). The mutational analysis of Avr9 has also shown that binding affinity of Avr9 for the HABS correlates with the ability of Avr9 to trigger Cf-9-dependent necrosis (Kooman-Gersmann et al. 1998), suggesting that the HABS could potentially mediate the interaction between Cf-9 and Avr9 by forming a complex with Avr9 (Fig. 1).

The region of Cf-9 controlling recognition of Avr9 has previously been narrowed down by a number of natural domain swaps (Thomas et al. 1997; van der Hoorn et al. 2001b) as well as engineered domain swaps and shuffled genes (van der

Table 1. Dramatis personce in the tomato-Cladosporium fulvum interaction

\begin{tabular}{|c|c|c|c|c|c|c|c|}
\hline \multirow[b]{2}{*}{ Resistance $^{\mathbf{a}}$} & \multicolumn{4}{|c|}{ Tomato proteins } & \multicolumn{2}{|c|}{ Cladosporium fulvum proteins } & \multirow[b]{2}{*}{ References } \\
\hline & Target $^{\mathrm{a}}$ & $\begin{array}{l}\text { Structure/ } \\
\text { function }\end{array}$ & $\begin{array}{l}\text { Other } \\
\text { targets }\end{array}$ & $\begin{array}{l}\text { Structure/ } \\
\text { function }\end{array}$ & Effector $^{\mathrm{a}}$ & $\begin{array}{l}\text { Structure/ } \\
\text { function }\end{array}$ & \\
\hline$\overline{\mathrm{Cf}-2}$ & Rcr3 & $\begin{array}{l}\text { Secreted cysteine } \\
\text { protease }\end{array}$ & PIP1 & $\begin{array}{l}\text { Secreted cysteine } \\
\text { protease }\end{array}$ & $\mathrm{Avr} 2^{\mathrm{b}}$ & $\begin{array}{l}\text { Secreted cysteine } \\
\text { protease inhibitor }\end{array}$ & $\begin{array}{l}\text { Dixon et al. } 1996 \text { (Cf-2) } \\
\text { Krüger et al. } 2002 \text { (Rcr3) } \\
\text { Luderer et al. } 2002 \text { (Avr2) } \\
\text { Tian et al. } 2007 \text { (PIP1) }\end{array}$ \\
\hline Cf-4 & None? & & None? & & $\operatorname{Avr} 4^{b}$ & $\begin{array}{l}\text { Secreted chitin-binding } \\
\text { protein }\end{array}$ & $\begin{array}{l}\text { Thomas et al. } 1997 \text { (Cf-4) } \\
\text { Joosten et al. } 1994 \text { (Avr4) }\end{array}$ \\
\hline Cf-4E & & & & & Avr4E & $\begin{array}{l}\text { Secreted cysteine-rich } \\
\text { protein }\end{array}$ & $\begin{array}{l}\text { Takken et al. } 1999 \text { (Cf-4E) } \\
\text { Westerink et al. } 2004 \text { (Avr4E) }\end{array}$ \\
\hline Cf-5 & & & & & (Avr5) & Unknown & Dixon et al. 1998 (Cf-5) \\
\hline Cf-9 & (HABS?) & & & & Avr9 ${ }^{b}$ & $\begin{array}{l}\text { Secreted cystine-knot } \\
\text { protein }\end{array}$ & $\begin{array}{l}\text { Jones et al. } 1994 \text { (Cf-9) } \\
\text { van den Ackerveken et al. } 1992 \\
(\text { Avr9) } \\
\text { Kooman-Gersmann et al. } 1996 \\
\text { (HABS) }\end{array}$ \\
\hline Cf-9B & $\begin{array}{l}\text { (ortholog of } \\
\text { NIP?) }\end{array}$ & $\begin{array}{l}\text { Secreted protein of } \\
\text { unknown function }\end{array}$ & & & (Avr9B) & Unknown & $\begin{array}{l}\text { Panter et al. } 2002 \text { (Cf-9B) } \\
\text { Chakrabarti et al. } 2009 \text { (NIP) }\end{array}$ \\
\hline (Cf-ECP1) & & & & & AvrECP $1^{b}$ & $\begin{array}{l}\text { Secreted cysteine-rich } \\
\text { protein }\end{array}$ & $\begin{array}{l}\text { Soumpourou et al. } 2007 \text { (Cf-ECP1) } \\
\text { van den Ackerveken et al. } 1993 \\
\text { (ECP1) }\end{array}$ \\
\hline (Cf-ECP2) & Probably & & & & AvrECP2 ${ }^{\mathrm{b}}$ & $\begin{array}{l}\text { Secreted disulphide- } \\
\text { bonded(?) protein }\end{array}$ & $\begin{array}{l}\text { Laugé et al. } 1998 \text { and } \\
\text { Haanstra et al. } 1999 \text { (Cf-ECP2) } \\
\text { van den Ackerveken et al. } 1993 \\
\text { (ECP2) }\end{array}$ \\
\hline (Cf-ECP4) & & & & & AvrECP4 & $\begin{array}{l}\text { Secreted cysteine-rich } \\
\text { protein }\end{array}$ & $\begin{array}{l}\text { Soumpourou et al. } 2007 \text { (Cf-ECP4) } \\
\text { Laugé et al. } 2000 \text { (ECP4) }\end{array}$ \\
\hline (Cf-ECP5) & & & & & AvrECP5 & $\begin{array}{l}\text { Secreted cysteine-rich } \\
\text { protein }\end{array}$ & $\begin{array}{l}\text { Haanstra et al. } 2000 \text { (Cf-ECP5) } \\
\text { Laugé et al. } 2000 \text { (ECP5) }\end{array}$ \\
\hline (Cf-ECP6?) & None? & & None? & & $\mathrm{ECP}^{\mathrm{b}}$ & $\begin{array}{l}\text { Secreted LysM domain } \\
\text { protein, possible } \\
\text { chitin-binding protein }\end{array}$ & Bolton et al. 2008 (ECP6) \\
\hline (Cf-ECP7?) & & & & & ECP7 & $\begin{array}{l}\text { Secreted cysteine-rich } \\
\text { protein }\end{array}$ & Bolton et al. 2008 (ECP7) \\
\hline ? & None? & & None? & & PhiA? & Phialide protein homolog & Bolton et al. 2008 (PhiA) \\
\hline
\end{tabular}

a Proteins shown in brackets correspond to genes that have not yet been isolated. Proteins shown with a question mark are either hypothetical in the case of the Cf-ECP6 or Cf-ECP7 proteins or their role as an effector or effector target is uncertain in the case of PhiA, the high-affinity Avr9 binding site (HABS) and the Nicotiana benthamiana necrosis-inducing protein (NIP).

${ }^{\mathrm{b}}$ Proteins shown to contribute to pathogenicity. 
Hoorn et al. 2001a; Wulff et al. 2001). In this issue of MPMI, Chakrabarti and associates (2009) and Wulff and associates (2009) have used domain swaps and gene shuffling between Cf-9 and Cf-9B to identify LRR13 through LRR15 of Cf-9 as a minimal region required for Avr9 recognition. Wulff and associates (2009) have also used a mutational approach to further show that four solvent-exposed $\beta$-strand residues (C387 and Y389 in LRR13, E411 in LRR14, and A433 in LRR15) are critical for Avr9 recognition. Residues in flanking LRR are also important for Avr9 recognition. Chakrabarti and Wulff and their associates (2009) have shown that residues in flanking LRR contribute quantitatively to Avr9 recognition, and van der Hoorn and associates (2001a) and Wulff and associates (2001) used domain swaps and gene shuffling between Cf-4 and Cf-9 to show that a fifth residue, L457 in LRR16, is also critical for Avr9 recognition.

\section{The Cf-9B-Nicotiana benthamiana} necrosis-inducing protein (NIP) interaction.

The $C f-9 B$ gene, conferring mature resistance to $C$. fulvum, is a homolog of $C f-9$ that confers recognition of the Avr9B effector, which has not yet been identified but might reasonably be expected to be a secreted cysteine-rich protein like all of the other $C$. fulvum effectors identified to date. The mature plant phenotype of Cf-9B is not caused by a lack of seedling expression (Panter et al. 2002) but is either a consequence of weak resistance requiring an increase in basal resistance coincident with the onset of flowering to be effective or requires a tomato protein expressed after the onset of flowering to mediate the interaction between $\mathrm{Cf}-9 \mathrm{~B}$ and Avr9B. The autonecrosis caused by the interaction between Cf- 2 and $\mathrm{Rcr} 3^{\text {esc }}$ is also a mature plant phenotype and is associated with increased expression of Rcr3 after the onset of flowering. Rcr3, targeted by Avr2, is involved in basal defense and satisfies the definition of a pathogenesis-related (PR) protein (Krüger et al. 2002; Shabab et al. 2008). An intriguing possibility is that Avr9B, like Avr2, targets a basal defense protein that is significantly upregulated or only expressed in mature plants. In this issue of MPMI, Chakrabarti and associates (2009) show that Cf-9B is able to recognize a necrosis-inducing factor present in the apoplast of Nicotiana benthamiana and that this recognition includes LRR in Cf-9B corresponding to those in Cf-4 and Cf9 determining recognition of Avr4 and Avr9, respectively. The necrosis-inducing factor is a protein (A. Chakrabarti and D. A. Jones, unpublished) that is, by analogy with $\operatorname{Rcr} 3^{\text {esc }}$ and Rcr3 ${ }^{\text {im }}$, likely to be a $N$. benthamiana variant of a protein targeted in tomato by Avr9B and kept under surveillance by Cf9B (Fig. 1).

Activation of Cf-9B also appears to involve a match between domains $\mathrm{N}$ - and $\mathrm{C}$-terminal to the domain required for recognition of the NIP. A domain swap containing the N-terminal half of Cf-9B (including the NIP recognition domain) and the C-terminal domain of Cf-9 did not trigger necrosis in $N$. benthamiana, whereas domain swaps containing the recognition domain of Cf-9B together with matching $\mathrm{N}$ - and $\mathrm{C}$ terminal flanking sequences from either Cf-9 or Cf-9B did

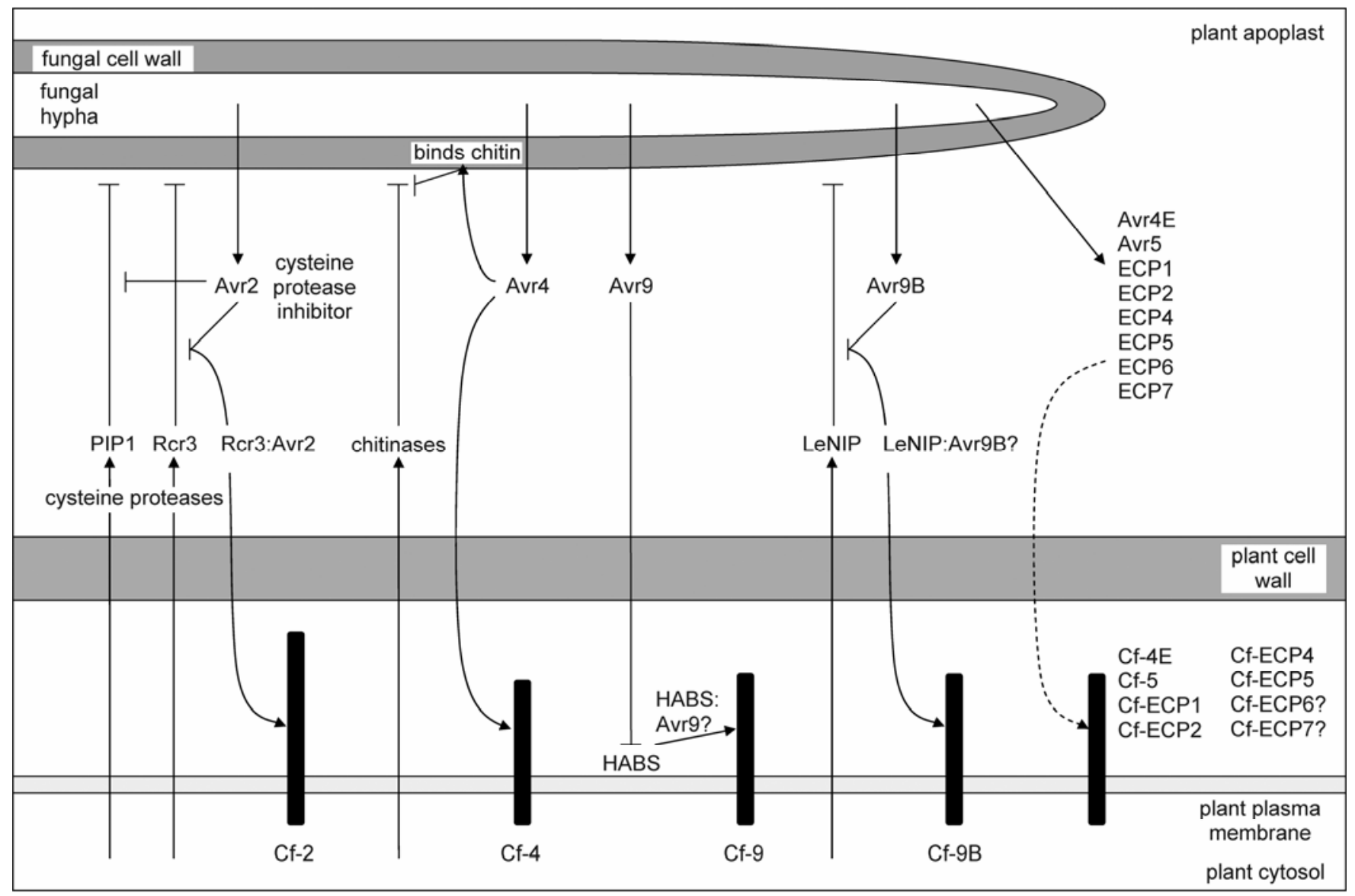

Fig. 1. All the leaf's a stage and all the Cladosporium fulvum (Cf)-resistance and avirulence (Avr) proteins merely players. The interactions between cognate pairs of tomato Cf-resistance proteins and C. fulvum Avr-extracellular protein (ECP) effectors are depicted in the apoplast of a tomato leaf. The plasma membrane and cell wall of a tomato cell are illustrated in the lower part of the figure and a $C$. fulvum hypha in the upper part. The molecular basis for recognition is shown without question marks if supported experimentally but with question marks when hypothesized. HABS = the membrane-bound high affinity Avr9 binding site. LeNIP = the putative tomato homolog of the Nicotiana benthamiana protein that triggers Cf-9B-dependent necrosis. 
trigger necrosis (Chakrabarti et al. 2009). This would seem to suggest that $\mathrm{N}$ - and $\mathrm{C}$-terminal domains of $\mathrm{Cf}$ proteins are coadapted and therefore might interact with one another (Fig. 2). The N-terminal flanking sequence of $\mathrm{Cf}-9$ comprising domain
B and LRR1 through LRR5 differs from that of Cf-9B by nine amino-acid substitutions and the insertion of a single amino acid in domain B and by 14 amino-acid substitutions in LRR2 through LRR5. Perhaps significantly, Cf-9 is glycosylated at
A

\section{Cf protein domains}

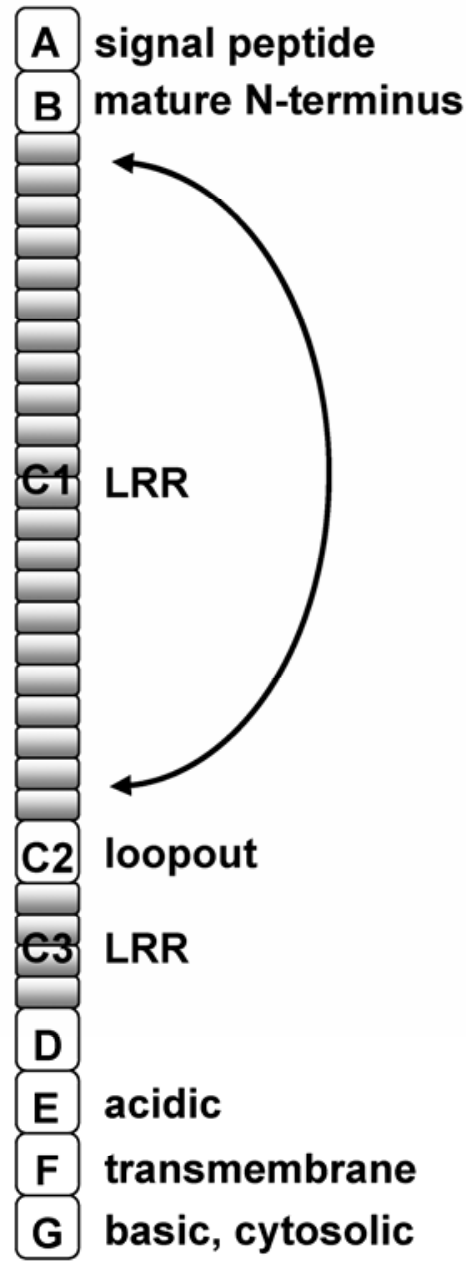

B
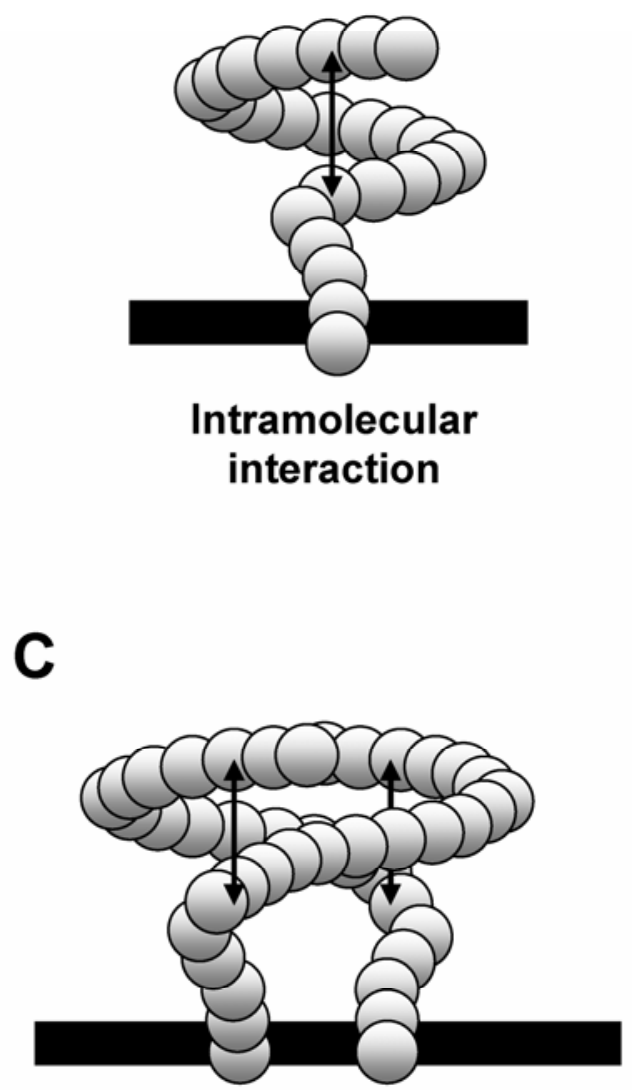

Reciprocal intermolecular interaction - dimerisation

D

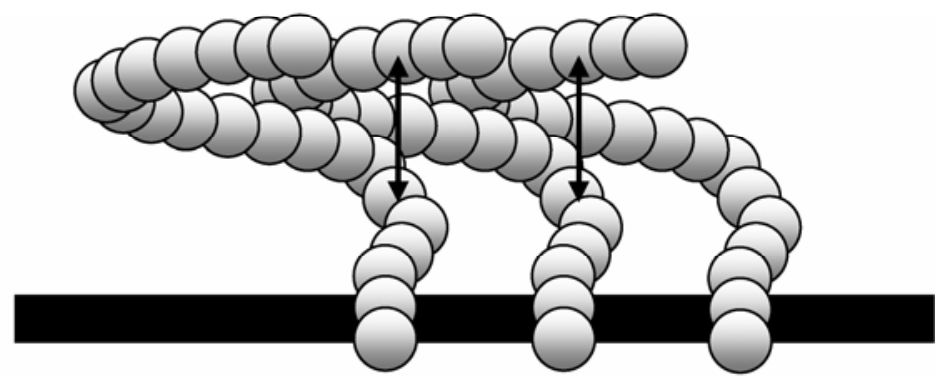

\section{Tandem intermolecular interaction - multimerisation}

Fig. 2. Models for interaction between the N- and C-terminal leucine-rich repeats (LRR) of the Cf-LRR domain of Hcr9 proteins. A, Diagram depicting the LRR structural domains of a Cf protein. The curved arrow links LRR subregions thought to interact with one another. Gray-shadowed rectangles represent individual LRR. Open rectangles represent non-LRR domains. B, Model for intramolecular interactions between the regions indicated with arrows in A, based on the superhelical structure predicted for Cf-9 by van der Hoorn and associates (2005). C, Model for reciprocal intermolecular interactions between the regions indicated by arrows in A in Cf protein dimers. D, Model for tandem intramolecular interactions between the regions indicated by arrows in A in Cf protein multimers. The black bars represent the plant plasma membrane. The chains of gray shadowed circles represent the Cf proteins. 
three N-glycosylation sites (van der Hoorn et al. 2005) missing in Cf-9B: one in domain B, one in LRR2, and the third in LRR3. If interacting $\mathrm{C}$-terminal domains have coadapted to these differences in glycosylation, then it may not be surprising that swapping the glycosylation pattern might disrupt an interaction required for normal $\mathrm{Cf}$ function.

Similarly, domain B of the Cf-4 protein appears to be important for recognition of Avr4 and activation of Cf-4 (van der Hoorn et al. 2001a). However, Wulff and associates (2001) were able to produce shufflants with $\mathrm{Cf}-4$ specificity and activity containing domain $\mathrm{B}$ sequences from $\mathrm{Cf}-9$, showing that the requirement for a matching domain $\mathrm{B}$ is not absolute. In this case, it is possible that nonadapted sequences introduced elsewhere in these shufflants may have compensated for the presence of domain B from Cf-9. Domain B from Cf-4 contains four amino-acid substitutions and a deletion of ten amino acids relative to $\mathrm{Cf}-9$, whereas domain $\mathrm{B}$ from $\mathrm{Cf}-9 \mathrm{~B}$ contains nine amino-acid substitutions and a deletion of one amino acid relative to Cf-9. While the deletion and not the amino-acid substitution seems to be important for Cf-4 function (van der Hoorn et al. 2001a; Wulff et al. 2001), it is probably the other way round for Cf-9B (Chakrabarti et al. 2009). These different requirements could reflect differences in recognition, e.g., in the aperture, shape, or specificity of the $\mathrm{Cf}$ protein-binding surface, but they could also reflect differences in the translation of recognition into $\mathrm{Cf}$-protein activation, e.g., through inhibitory molecular interactions or by facilitating conformational changes required for activation following recognition.

\section{The Cf-4-Avr4 interaction.}

The C. fulvum Avr4 protein is a secreted, cysteine-rich protein (Joosten et al. 1994) containing four disulphide bonds (van den Burg et al. 2001) that contribute to the stability of Avr4 in the proteinase-rich apoplast of the tomato leaf (van den Burg et al. 2003; Westerink et al. 2004). Unlike most other effectors, which actively interfere with host cellular processes, Avr4 is a passive effector. It binds cooperatively to chitin and thereby protects the fungal cell wall from attack by plant chitinases (Fig. 1; van den Burg et al. 2003, 2004, 2006). Expression of Avr4 in planta is sufficient by itself to trigger a Cf-4dependent response (Thomas et al. 2000), indicating that chitin binding is not required for Avr4 recognition by Cf-4. Analysis of a limited number of natural and site-directed mutants of Avr4 has, so far, failed to identify residues required for chitin binding or recognition by Cf-4 (Joosten et al. 1997; Westerink 2003), but a physicochemical analysis indicates that a cluster of six amino acids (N93, D94, N95, W100, D102, and Y103) is involved in chitin-binding (van den Burg et al. 2004). In the apparent absence of natural mutations that abolish Avr4 recognition without affecting protein stability or chitin binding and, given that chitin binding is likely to be a conserved feature of Avr4, it is tempting to speculate that these residues may also be involved in recognition by $\mathrm{Cf}-4$.

Cf-4 is thought to interact directly with Avr4 (Fig. 1), but no binding experiments showing a direct interaction have been reported. It is conceivable that Avr4 could have a dual function as both a chitin-binding protein and an active effector. The evidence that Avr4 does not target a host protein is indirect and is based on a lack of transcriptional activation following expression of Avr4 in plants lacking Cf-4 (van Esse et al. 2007). Many effectors cause post-translational modifications that need not cause transcriptional effects. The question of direct or indirect interaction between Cf-4 and Avr4 therefore remains to be resolved.

Many of the domain swap and gene-shuffling experiments designed to narrow down the region of Cf-9 responsible for recognition of Avr9 were also designed to narrow down the region of Cf-4 responsible for Avr4 recognition (van der Hoorn et al. 2001a; Wulff et al. 2001). These studies showed that the absence in Cf-4 of two LRR present in Cf-9 (LRR11 and LRR12) was essential for Cf-4 function but not sufficient by itself for Avr4 recognition. The requirement for this deletion could suggest that a difference in the shape or aperture of the binding surface is necessary to accommodate the ligand involved in Avr4 recognition, as opposed to the ligand involved in Avr9 recognition. van der Hoorn and associates (2001a) also used a mutational approach to further show that three solventexposed $\beta$-strand residues (W332 in LRR11, G354 in LRR12, and F400 in LRR14 of Cf-4) are critical for Avr4 recognition. In this issue of MPMI, Wulff and associates (2009) show that three of the five residues required for Avr9 recognition by Cf- 9 correspond to these three residues required for Avr4 recognition by Cf-4 (Y389 in LRR13 of Cf-9 corresponds to W332 in LRR11 of Cf-4, E411 in LRR14 of Cf-9 corresponds to G354 in LRR12 of Cf-4, and L457 in LRR16 of Cf-9 corresponds to F400 in LRR14 of Cf-4).

\section{The Cf-ECP-ECP interactions and other $\mathbf{C f}-\mathbf{A v r}$ interactions.}

At least seven secreted extracellular proteins (ECP) have been identified for C. fulvum (Table 1; Fig. 1), and several (ECP1, ECP2, and ECP6) have been shown to play a role in pathogenicity (Bolton et al. 2008; Laugé et al. 2000; van den Ackerveken et al. 1993; Wubben et al. 1994). Most encode small cysteine-rich proteins of unknown function, but CfPhiA is a homolog of an Aspergillus protein necessary for phialide development and sporulation, and ECP6 encodes a larger protein containing three lysM carbohydrate-binding domains that may bind chitin (Bolton et al. 2008). Potentially, any chitin-binding capability of ECP6 could be redundant with that of Avr4, but this seems not to be the case, because RNAi silencing of ECP6 reduced the virulence of $C$. fulvum race 5 despite the presence of Avr4 (Bolton et al. 2008) and silencing of Avr4 reduced the virulence of C. fulvum race 4, which expresses an unstable form of Avr4 still able to bind chitin, despite the presence of ECP6 (van Esse et al. 2007). Resistance genes conferring recognition of ECP1, ECP2, ECP4, and ECP5 have been identified from L. pimpinellifolium and were found to map to clusters of $\mathrm{Hcr} 9$ (homologs of Cladosporium-resistance gene $C f-9$ ) genes located on the short arm of tomato chromosome 1 (Fig. 3) (Haanstra et al. 1999, 2000; Laugé et al. 1998b, 2000; Soumpourou et al. 2007). As presumptive homologs of Cf-4, Cf-9, and Cf-9B, it is likely that the recognitional specificities of Cf-ECP1, Cf-ECP2, Cf-ECP4, and Cf-ECP5 reside in the corresponding LRR and may involve variant residues at some of the same positions that determine $\mathrm{Cf}$ 4 or Cf- 9 specificity. However, it is curious that all of the $C f$ $E C P$ resistance genes that have been mapped so far seem to be $\mathrm{Hcr} 9$ genes and none $\mathrm{Hcr} 2$ genes. Is this coincidence or does it reflect a difference in the recognitional capabilities of Hcr9 versus Hcr2 proteins? The length of the repeats is more highly conserved in the LRR of the Hcr2 proteins than in those of Hcr9 proteins and the Hcr2 proteins show an alternating pattern of repeats that is absent from the Hcr9 proteins. It is conceivable that the conservation of these features may serve an adaptive purpose on the one hand but limit the capacity to generate new recognitional specificities on the other.

This leaves two additional Cf-Avr combinations, Cf-5-Avr5 and Cf-4E-Avr4E, that have not been extensively characterized (Table 1; Fig. 1). The tomato $C f-5$ gene has been isolated, but the corresponding $C$. fulvum Avr5 gene has not. Thus, little is known about the recognitional capacity of Cf-5 apart from the information generated by domain swaps with $\mathrm{Cf}-2$, which showed that the recognitional specificity of Cf-5 lies between LRR3 and LRR21 (Seear and Dixon 2003). Both the tomato 
$C f-4 E$ and $C$. fulvum Avr4E genes have been isolated. The Avr $4 E$ gene encodes a small secreted cysteine-rich protein of unknown function (Westerink et al. 2004). Almost nothing is known about the recognition of Avr4E, apart from the finding that the amino-acid substitution F82L eliminates recognition of Avr4E by Cf-4E without affecting the stability of Avr4E, suggesting that the amino acid residue F82 plays a critical role in Avr4E recognition (Westerink et al. 2004).

Heterologous expression and defense activation by Cf proteins and their cognate Avr or ECP proteins.

Heterologous expression of the L. pimpinellifolium $C f-2$ gene in L. esculentum leads to autonecrosis in mature plants, owing to the absence of the coadapted Rcr3 gene from $L$. pimpinellifolium and the presence of the nonadapted Rcr3 gene from L. esculentum (Krüger et al. 2002). In theory, this autonecrosis could have been used as a marker for the mapbased cloning of either $C f-2$ or Rcr3. Thus, heterologous perturbations of the tightly regulated connection between recognition and signal activation could be useful for the identification and isolation of additional components involved in recognition. However, if there is a direct interaction between $\mathrm{Cf}$ protein and Avr protein, heterologous expression of the $\mathrm{Cf}$ protein alone would not be expected to trigger necrosis, because no other plant components are involved in recognition. The inter- action between Cf-4 and Avr4 is thought to be direct, and to date, heterologous expression of $\mathrm{Cf}-4$ has not caused autoactivation in any plant species tested even though it is able to activate a necrotic response in a number of species when coexpressed with Avr4 (Hammond-Kosack et al. 1998; Thomas et al. 2000; van der Hoorn et al. 2000; Wulff et al. 2004a). For solanaceous plants, the pattern of responses to Cf- 9 alone or in combination with Avr9 is largely a mirror image of the response to $\mathrm{Cf}-4$ alone or in combination with Avr4 (van der Hoorn et al. 2000; Wulff et al. 2004a). Based on the assumption that the Cf-4-Avr4 interaction is direct, it could therefore be argued that Cf-9-Avr9 interaction is also direct, except for the observation that the HABS for Avr9 is present in all solanaceous plants (Kooman-Gersmann et al. 1996). The critical difference between Cf- 9 and Cf- 4 is the observation for lettuce, which responds to $\mathrm{Cf}-4 / \mathrm{Avr} 4$ interaction but not to $\mathrm{Cf}-9-\mathrm{Avr} 9$ interaction. Given the evidence that $\mathrm{Cf}-4$ and $\mathrm{Cf}-9$ signal through the same signal transduction pathway (summarized by Fradin and associates [2009]), Cf-9 should also be able to activate a defense response in lettuce, if there was a direct interaction with Avr9. Presumably the failure of the Cf-9-Avr9 combination to do so can be attributed to the absence of the HABS in lettuce as shown by Kooman-Gersmann (1998).

In contrast to $C f-4, C f-9$ and a number of other Hcr 9 genes, heterologous expression of $\mathrm{Cf}-9 \mathrm{~B}$ and the Hcr9 genes Perul
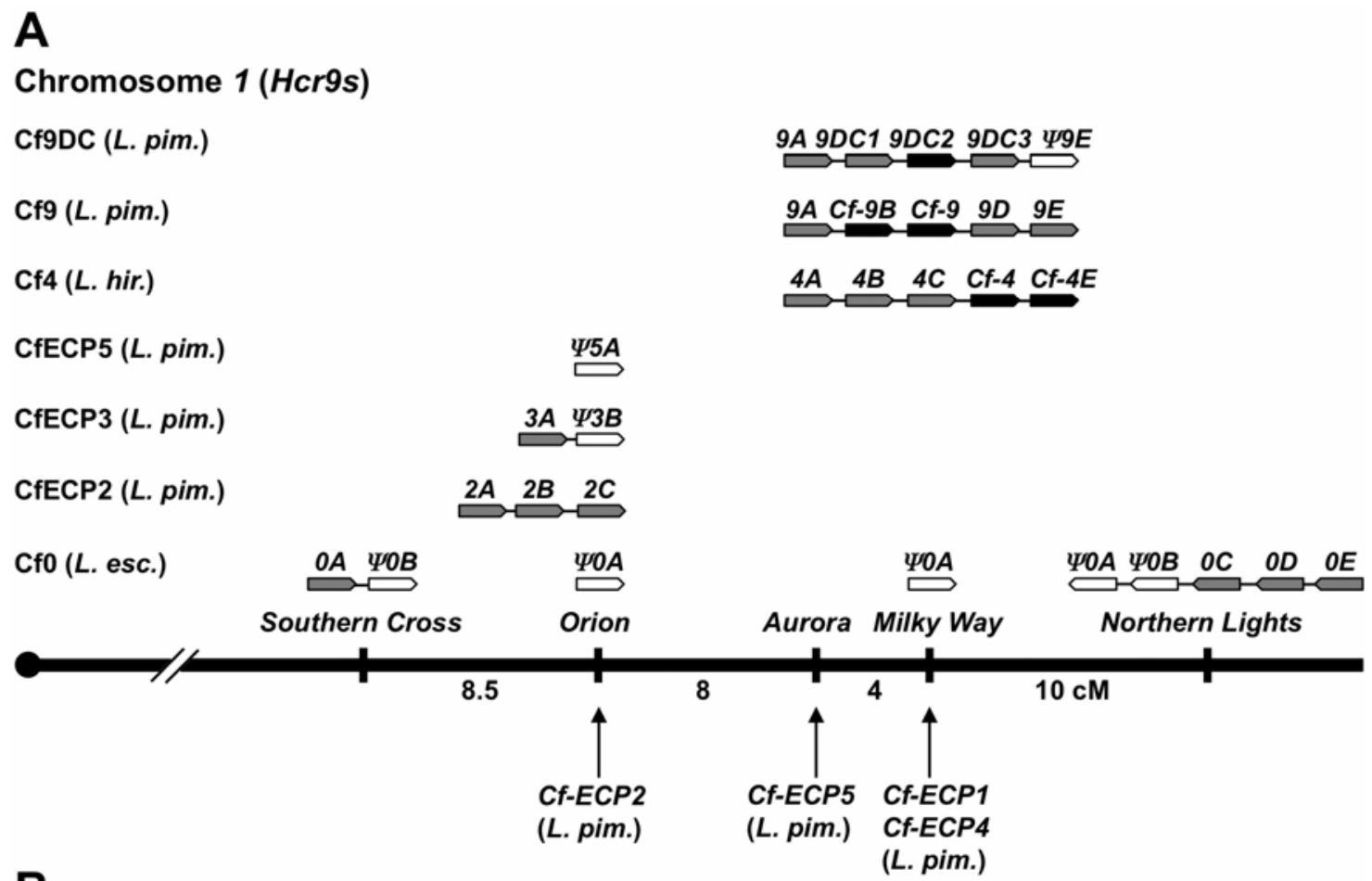

B

Chromosome 6 (Hcr2s)

Cf0 (L. esc.)
Cf2 (L. pim.)
Cf5 (L. esc. var. cer.)

$O A O B$

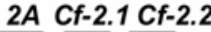

$5 A \quad 5 B \quad$ Cf $-5 \quad 5 D \quad 5 E$
9A 9DC1 9DC2 9DC3 $49 E$
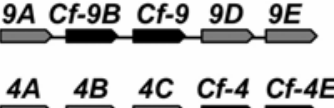

$\Psi 5 A$

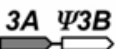

$2 A \quad 2 B \quad 2 C$ 
and Peru 2 triggers necrosis in a number of Nicotiana species (Chakrabarti et al. 2009; Wulff et al. 2004a). As already discussed for Cf-9B, this could potentially reflect the detection of Nicotiana proteins that are variants of Lycopersicon proteins kept under surveillance by these Hcr9 proteins. However, Wulff and associates (2004a) have also shown that it is possible to generate chimeric $\mathrm{Hcr} 9$ genes that are able to trigger necrosis when expressed in some or all of these Nicotiana species. In these autoactive chimeras, it is possible that the interaction between domains involved in recognition and signal activation necessary for tight regulation of signaling have been disrupted by the introduction of nonadapted sequences from other Hcr9 genes. These disruptions could, in turn, be useful for the separation of intra- or intermolecular interactions involved in recognition from those involved in signal activation.

A reanalysis of the autoactive chimeras generated by Wulff and associates (2004a) suggests that specific combinations of variant residues in LRR2 and LRR21 may contribute to autoactivity (Supplementary material). Interestingly, in the superhelical model of Cf-9 structure presented by van der Hoorn and associates (2005), the position that would be occupied by the variant residue in LRR2 is in a downward-facing position almost directly above the upward-facing position that would be occupied by the variant residue in LRR21 (representing one turn of the superhelix). Is this juxtaposition sheer chance, or could the superhelical structure be flexible enough for residues at these positions to contact one another? The superhelical structure of LRR proteins can alter curvature and twist to accommodate cognate ligands (Kobe and Deisenhofer 1995), so it may be possible for intramolecular contacts to occur between apparently distal parts of the Cf-9 protein (Fig. 2). Potentially, the variant residues in these positions could disrupt an intra- or intermolecular interaction between the $\mathrm{N}$ - and $\mathrm{C}$ terminal extremes of the C1 LRR domain that might normally help to keep the Cf protein in an inactive state (Fig. 2). Interestingly, the LRR domain of nucleotide binding site (NBS)LRR resistance proteins is also thought to be involved in both effector recognition and inhibitory intramolecular interactions (Padmanabhan et al. 2009).

Heterologous expression of C. fulvum Avr or ECP genes in plants may also give insights into the components of recognition. Heterologous expression of $E C P$ genes has been used successfully to identify cognate $C f-E C P$ genes in $L$. pimpinellifolium (Haanstra et al. 1999, 2000; Laugé et al. 1998b, 2000) and will no doubt contribute to their eventual isolation (Soumpourou et al. 2007). Heterologous expression might likewise enable identification of additional plant components required for recognition. If there is no effector target in the host plant, heterologous expression of the Avr or ECP protein alone in nonhost plants would not be expected to trigger necrosis, because there would have been no selection pressure driving the evolution of direct recognition of an effector from a nonpathogen. Avr4 does not appear to have a host target and, to date, heterologous expression of Avr4 has not caused defense activation in any nonhost plant tested (Laugé et al. 2000; van Esse et al. 2007). If there is an effector target in the host plant, heterologous expression of the Avr or ECP protein alone in nonhost plants would not be expected to trigger necrosis by direct recognition because, again, there would have been no selection pressure for the evolution of direct recognition of an effector from a nonpathogen. Heterologous expression of Avr9 has been found to trigger necrosis in the nonhost plants Solanum hannemanii and S. leptophyes (Kruijt et al. 2005a), suggesting indirect recognition of Avr9, perhaps through the HABS. However, these Solanum species share a relatively recent common ancestry with Lycopersicon species (recently reclassified as Solanum species), and it is possible that the ancestor of C. ful- vum was a pathogen on the common ancestor of the genera Solanum and Lycopersicon, so direct recognition cannot be ruled out, especially as the presence of $C f-9$ predates the divergence of Lycopersicon species from one another (Kruijt et al. 2005a). On the other hand, heterologous expression of ECP2 has been found to trigger necrosis in the more-divergent nonhost plants Nicotiana paniculata, N. sylvestris, N. tabacum, and N. undulata (de Kock et al. 2004; Laugé et al. 2000), suggesting more strongly indirect recognition of ECP2 mediated by an ECP2 target protein kept under surveillance by the functional equivalent of a Cf-ECP2 protein.

\section{MOLECULAR AND EVOLUTIONARY MECHANISMS THAT DRIVE VARIATION IN RECOGNITIONAL SPECIFICITY IN THE TOMATO-C. FULVUM PATHOSYSTEM.}

To infect the host and complete its life cycle, $C$. fulvum must avoid detection by the host's surveillance machinery, protect itself against the harsh chitinase- and protease-rich environment of the apoplast, and subvert host metabolism to support its own growth and reproduction. To achieve these tasks, the fungus secretes a suite of effector proteins (Fig. 1). The plant, in turn, has evolved $C$. fulvum-resistance genes, whose protein products continuously monitor the extracellular matrix and elicit an immune response upon effector detection (Fig. 1). This scenario leads to an evolutionary antagonism between the pathogen and the host; the pathogen is under pressure to escape detection, while the host strives to maintain a capacity for pathogen detection.

\section{C. fulvum-resistance gene variation.}

Studies on the evolution of the tomato-C. fulvum pathosystem have relied heavily on the characterization of near-isogenic lines of cultivated tomato ( $L$. esculentum) containing $C$. fulvum-resistance genes introgressed from wild relatives, and the study of races of $C$. fulvum that were found to have overcome these resistances in greenhouse or field-grown tomatoes (Rivas and Thomas 2005). The identification of $C f-9$ by transposon tagging (Jones et al. 1994) and $C f-2$ by positional cloning (Dixon et al. 1996) paved the way for the subsequent isolation and characterization of whole haplotype assemblies of these loci in several different introgression lines and accessions of tomato (Dixon et al. 1998; Kruijt et al. 2004; Parniske and Jones, 1999; Parniske et al. 1997, 1999).

Gel-blot analysis using the $C f-9$ gene as a probe revealed that $C f-9$ belongs to a multigene family with approximately 16 members (Jones et al. 1994). Five distinct Hcr9 loci have since been mapped to the short arm of chromosome 1 (Fig. 3) (Kruijt et al. 2005b), whereas a single locus of the structurally related $\mathrm{Hcr} 2$ genes has been mapped to chromosome 6 (Fig. 3) (Caicedo and Schaal 2004; Dickinson et al. 1993; Dixon et al. 1996).

The $C f-9$ gene (introgressed from $L$. pimpinellifolium) resides at the Milky Way (MW) locus and is the third Hcr9 gene (Hcr9$9 C)$ in a complex haplotype containing five paralogs named Hcr 9-9A to Hcr9-9E, of which $9 B$ is also a functional resistance gene (Fig. 3) (Panter et al. 2002; Parniske et al. 1997). The $C f-4$ gene (introgressed from $L$. hirsutum) also resides at the $M W$ locus and is the fourth member (Hcr9-4D) in a five-member haplotype, in which $4 E$ is also a functional resistance gene (Parniske et al. 1997; Takken et al. 1999). There is a single, nonfunctional homolog $(\mathrm{Hcr} 9-\psi 0 A)$ at the $M W$ locus in the susceptible Cf0 line of L. esculentum (Parniske et al. 1997).

Alignment of the Hcr 9 genes at the $M W$ locus revealed that within their conserved protein-encoding framework, they consist of a patchwork of stretches of shared sequences, indicating that 
one mechanism that generates $H c r 9$ gene variation is sequence exchange between paralogs through unequal crossing over or gene conversion (Fig. 4A) (Parniske et al. 1997). A survey of wild L. pimpinellifolium accessions for Avr9 recognition allowed the recovery of a gene designated $9 D C$, which appears to be a chimera between the Hcr $9-9 D$ and $C f-9$ paralogs at $M W$ (Kruijt et al. 2004; van der Hoorn et al. 2001b). The observation that the $C f-4$ and $C f-9$ genes are diverged in their $5^{\prime}$ halves $(92 \%$ identity) but near identical in their $3^{\prime}$ halves also suggests recombination with a common progenitor (Thomas et al. 1997).

A Intra-locus unequal crossover and gene conversion

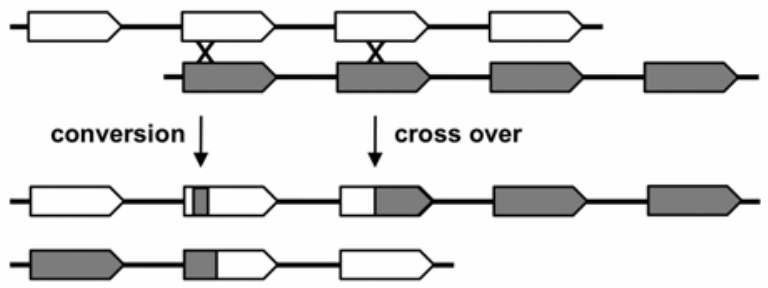

B Inter-locus recombination followed by intra-locus recombination

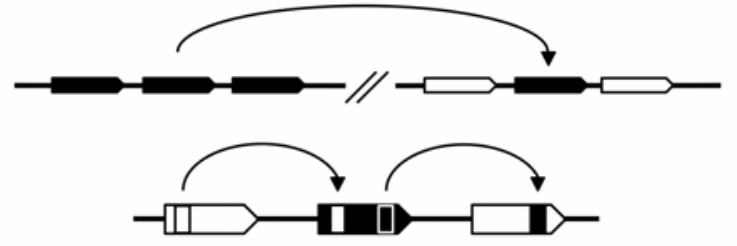

C Consequences of unequal crossover and gene conversion

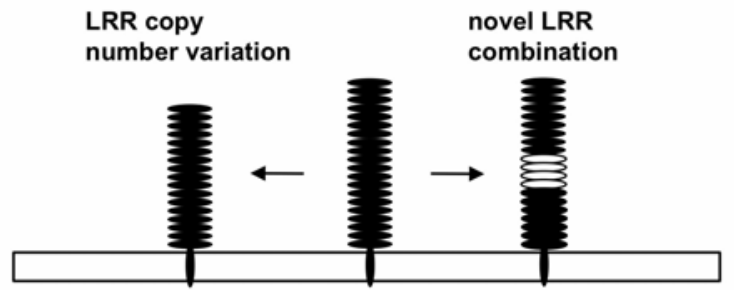

D Diversifying selection at LRR interaction surface

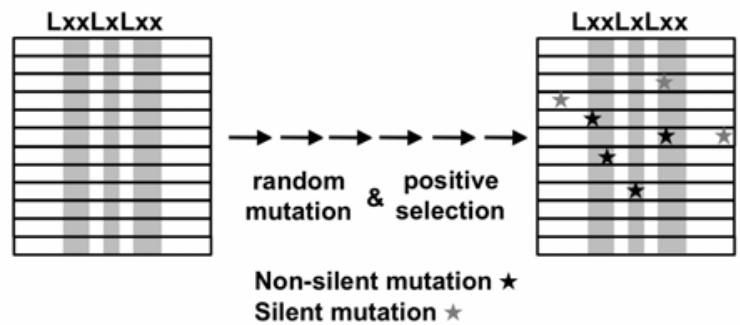

Fig. 4. Molecular and evolutionary mechanisms that generate $H c r 9$ variation. A, Mispairing during meiosis followed by crossing over or gene conversion leads to novel $\mathrm{Hcr} 9$ sequence combinations and allows pyramiding of multiple specificities. Subsequent rounds of recombination can lead to segmental exchanges (not shown). B, Occasionally, sequence-distinct $\mathrm{Hcr} 9$ genes that have evolved in chromosomal isolation may be recruited to a different locus by interlocus recombination, thus increasing the scope for genetic novelty by subsequent intralocus recombination. C, The consequences of $H c r 9$ unequal crossing over and gene conversion are chimeric Hcr9 proteins with variation in leucine-rich repeat (LRR) copy number or new combinations of LRR. D, Random mutation followed by positive selection for variation at putative solvent-exposed residues in the $\beta$-strand/ $\beta$ turn structural motif of the LRR (LxxLxLxx) is likely also an important source of variation. A and B, modified from Parniske and associates (1997) and Parniske and Jones (1999), respectively.
There is also evidence for past sequence exchange between members of the $M W$ locus and diverged $H c r 9$ genes at the distal Northern Lights locus, which is separated from $M W$ by $10 \mathrm{cM}$ (Parniske and Jones 1999). Thus, Hcr9 genes that evolve in relative chromosomal isolation can occasionally introduce genetic novelty to a distant locus (Fig. 4B).

The tandemly duplicated gene structure of the Hcr9 loci allows the pyramiding of multiple specificities at the same locus, such as $C f-9$ and $C f-9 B$, or $C f-4$ and $C f-4 E$, both at $M W$ (Fig. 3). Unequal crossing over between haplotypes likely also contributes to pyramiding. For example, susceptible recombinants occur at the high rate of 1 per 2,000 plants among the testcross progeny of a $C f-4-C f-9$ heterozygote (Parniske et al. 1997; Wulff et al. 2004b). However, the reciprocal product of meiosis (which was not recoverable in these screens) would be a predicted eight-member haplotype carrying four functional resistance $(R)$ genes in cis, namely $C f-9 B, C f-9, C f-4$, and $C f$ $4 E$. Such complex loci with multiple specificities are likely to be more demanding for the fungus to overcome.

LRR copy number is also an important Hcr 9 specificity determinant (van der Hoorn et al. 2001a; Wulff et al. 2001). The Hcr 2 and Hcr5 proteins contain tandem repeats of two highlyconserved LRR designated types A and B (Dixon et al. 1996), which usually alternate with one another and are flanked on the N-terminal side by four non-A or B LRR and on the C-terminal side by 18 non-A or B LRR. Extreme intralocus, intraspecific, and interspecific variation in $\mathrm{AB}$ repeat number has been documented at this locus, with members encoding 3, 4, 7, 9, 13, 15, or 20 A or B LRR (Caicedo and Schaal 2004; Dixon et al. 1996, 1998). The regular structure of the AB repeat was postulated to provide increased potential for unequal crossover or tandem duplication due to slippage during DNA replication (Dixon et al. 1998). The observation that there is no correlation between repeat divergence and position suggests that the repeat number variation has been generated principally by unequal crossover rather than tandem duplication (Caicedo and Schaal 2004). In contrast to the Hcr2 genes, the LRR encoded by $H c r 9$ genes are all distinct from each other, reducing the scope for unequal crossover. However, while most members encode 27 LRR (30 out of 39), some variation is observed with individual Hcr9 genes encoding 23, 25, and 32 LRR (de Kock et al. 2005; Kruijt et al. 2004; Parniske and Jones 1999; Parniske et al. 1997; Wulff et al. 2004a).

The identification of functional and sequence near-identical Cf-4 and Cf-9 homologs in wild Lycopersicon species suggest that these genes are ancient and predate speciation (Kruijt et al. 2005a). Furthermore, despite the differences between Hcr2 and Hcr9 proteins, there is high homology in the $3^{\prime}$ portion of their genes, and the exon-intron structure is conserved (Dixon et al. 1996), indicating that the Hcr2 and Hcr9 genes arose from a common, ancient ancestor.

Selection for nonsynonymous nucleotide substitutions in sequences encoding the putative solvent-exposed residues of the conserved $\beta$-strand/ $\beta$-turn LRR structural motif also contributes to Hcr9 sequence variation (Fig. 4D) (Parniske et al. 1997). Polymorphic residues between Cf-4 and Cf-9 that determine specificity occupy the same positions in the two proteins and coincide with the most variable positions in a global Hcr9 alignment, further supporting the importance of divergent selection for generating novel specificities (Wulff et al. 2009).

The combination of random mutation, divergent selection, and recombination allows successful mutations selected in one $R$ gene to be tested out in another. In molecular biology, as in nature, this has proven a very powerful strategy to improve protein function in vitro by the process of gene shuffling (Crameri et al. 1998; Stemmer 1994). 
In conclusion, the Hcr9 and Hcr2 families evolve by duplication, mutation, and divergent selection at putative solventexposed residues in the LRR, sequence exchange between divergent homologs, and unequal crossing over that leads to variation in LRR sequence and copy number (Fig. 4).

\section{C. fulvum effector gene variation.}

To date, 11 different ECP and Avr genes have been cloned (Table 1), and at least a eight more are predicted, based on distinct gene-for-gene interactions including Avr1, Avr3, Avr5, Avr6, Avr7, Avr10, Avr11 (Stevens and Rick 1988), and Avr9B (Laugé et al. 1998a; Panter et al. 2002; Parniske et al. 1997). The characterized effectors are likely either the most abundantly secreted and stable proteins, those matching strong $C$. fulvum-resistance genes deployed in cultivated tomato, or both. In terms of the total number of effectors, they may only represent the tip of the iceberg. The C. fulvum genome has not yet been fully sequenced. Acquisition of the genome sequence would be useful to estimate the total effector complement, based on the occurrence of genes encoding predicted secreted, small cysteine-rich proteins.

The $A v r$ genes have accumulated many more polymorphisms than the ECP genes (Bolton et al. 2008; Stergiopoulos et al. 2007b). This is likely because the commercial use of matching $R$ genes has created evolutionary pressure for the selection of variation in the corresponding Avr genes and only $C$. fulvum strains isolated from areas of commercially grown tomato have been sampled (Stergiopoulos et al. 2007b). In contrast, $C f-E C P$ genes have not yet been deployed on a large scale. It is, therefore, perhaps not surprising that most genetic variation identified in $E C P$ genes encodes synonymous substitutions (Bolton et al. 2008; Stergiopoulos et al. 2007b), because in the absence of a matching $R$ gene, loss of ECP function would be likely to incur a virulence penalty. Indeed, loss of $\mathrm{ECP} 1, \mathrm{ECP} 2$, and ECP6 has been shown to reduce virulence on susceptible tomato (Bolton et al. 2008; Laugé et al. 1997).

Variation in $A v r$ genes that allows the fungus to escape detection by the corresponding $C f$ genes includes nonsense mutations (Avr2 and Avr4), missense mutations (Avr4 and Avr4E), transposon insertion $(A v r 2)$, and whole gene deletions (Avr4E and Avr9) (Joosten et al. 1994, 1997; Luderer et al. 2002; van den Ackerveken et al. 1992; Westerink et al. 2004). The observation that the fungus can jettison an effector indicates only a minor virulence penalty. This could be due to partial functional redundancy with other effectors or simply because a single effector exerts only a minor effect in relation to the whole effector complement. Lindhout and associates (1989) described the occurrence of a race that had evolved to overcome resistance genes $C f-2, C f-4, C f-5, C f-9$, and $C f-11$. Since this race has not spread and become the dominant race, this would argue that there is a severe fitness penalty associated with the combined loss of so many effectors.

The occurrence of a transposon-inactivated allele of Avr2 (Luderer et al. 2002) may reflect the location of Avr2 in a transposon-rich region of the genome, providing increased scope for genetic plasticity. This notion is supported by the observation that genes encoding the effectors of plant-pathogenic fungi often localize in unstable transposon-rich and telomeric regions of the genome (Hougenhout et al. 2009).

Circumvention of recognition by $\mathrm{Cf}-4$ has generally been achieved by selection for adaptive missense mutations. These mutant Avr4 proteins retain functionality as chitin-binding proteins but are rendered less stable in the apoplast, so that they are degraded before being detected by Cf-4 (van den Burg et al. 2003). This suggests that Avr4 is an important virulence determinant, a notion that has been experimentally confirmed by silencing of Avr4 (van Esse et al. 2007).
No sexual stage has been observed in C. fulvum, but the recent identification of two opposite mating-type genes and DNA sequence analysis of different strains does not support a purely clonal propagation (Stergiopoulos et al. 2007a and b). Thus, meiotic recombination, if it occurs, could provide a means of generating genetic variation including novel combinations of functional or nonfunctional ECP and Avr genes.

A survey of $E C P$ and $A v r$ gene variation in wild accessions of $C$. fulvum might give insights into the adaptive evolution of $E C P$ and $A v r$ genes in nature. Furthermore, the analysis of natural and induced variation in $C$. fulvum strain effector complement might be used as a strategy to identify putative functional redundancy between pairs or multiple combinations of effectors, as has recently been done in Pseudomonas syringae pv. tomato DC3000 (Kvitko et al. 2009). The number of functional redundancy groups would also hint at the number of host functions targeted by C. fulvum effectors.

\section{Variation in proteins monitored by tomato Cf proteins targeted by $C$. fulvum effector proteins.}

The guard model proposed by van der Biezen and Jones (1998) and elaborated by Dangl and Jones (2001) postulates that some $\mathrm{R}$ proteins monitor a pathogen effector target rather than interact directly with their cognate pathogen effector. If a pathogen effector mutates to enable modification of the guardee without being detected by the guard, then the guard and guardee duo come under evolutionary pressure to regain recognition capacity or avoid modification by the effector or both. To date, the Cf-2-Rcr3-Avr2 interaction is the only well-characterized example of an interaction in the tomato- $C$. fulvum pathosystem that conforms to the guard hypothesis. Consistent with the guard hypothesis, Rcr3 has the hallmarks of pathogen-driven positive selection. First, it belongs to a multigene family that resides in a complex locus with five paralogs (Krüger et al. 2002), including the Phytophthora-inhibited protease-1 (Pip1), which is also targeted by Avr2 (Shabab et al. 2008; Tian et al. 2007). Second, there is evidence for divergent selection in and around the substrate-binding grooves in Rcr3 and Pip1 (Shabab et al. 2008).

Positive selection could act in several possible ways. It could drive variation in the substrate specificity of the cysteine protease activity of Rcr3. Conceivably, the cysteine protease activity of Rcr3 exerts selective pressure on the pathogen favoring substrate variation, necessitating adaptive changes in Rcr3 to keep pace. Variation in Rcr3 might also reflect adaptive changes to avoid inhibition by pathogen inhibitors. This seems unlikely, given that $\mathrm{Rcr} 3^{\mathrm{esc}}$ and $\mathrm{Rcr} 3^{\text {pim }}$ are both inhibited by Avr2 and the introduction of three variant amino acids from other Rcr3 variants into Rcr3 ${ }^{\text {esc }}$ does not affect Avr2 binding (Shabab et al. 2008), although it is possible that these Rcr3 variants are affected differently by other pathogen inhibitors such as EPIC1 and EPIC2B. Conversely, the introduction of a variant amino acid present in L. chmielewskii Rcr3 renders the protein insensitive to Avr2 inhibition (Shabab et al. 2008). Variation in Rcr3 might also reflect adaptive changes necessary to ensure that inhibitor binding triggers a $\mathrm{Cf}-2$ response. It is possible that there is selective pressure on Avr2 and other Rcr3 inhibitors to bind and inhibit Rcr3 in such a way as to avoid triggering $\mathrm{Cf}-2$ activation, necessitating adaptive variation in Rcr3 to ensure inhibitor binding does trigger Cf- 2 activation. Shabab and associates (2008) have suggested that the variation in Rcr3 may reflect adaptive changes required to avoid triggering activation of $\mathrm{Cf}-2$ or its homologs inappropriately. However, if Rcr3 variation is being driven by pathogen effector variation, then it is just as likely that variation occurs in $\mathrm{Cf}-2$ in order to maintain the capacity to both recognize variant Rcr3:Avr2 complexes and avoid inappropriate activation. 
The interaction between Cf-2, Rcr3, and Avr2 has also been cited as evidence supporting the decoy hypothesis proposed by van der Hoorn and Kamoun (2008), which postulates that some resistance proteins monitor proteins similar to those targeted by pathogen effectors but lacking their functionality. In the case of Avr2, it has been argued that Pip1 is the true target and Rcr3 merely a decoy (Shabab et al. 2008). However, while the decoy hypothesis may fit other interactions, Song and associates (2009) have shown that a null mutant of Rcr3 confers increased susceptibility to Phytophthora infestans, indicating that Rcr3 does play an active role in plant defense and is not just a decoy.

The observation that $\mathrm{Cf}-2$ triggers necrosis in tomato plants carrying the $R c r 3^{e s c}$ allele but not the $R c r 3^{\text {pim }}$ allele (Krüger et al. 2002) is reminiscent of the finding that Hcr9 alleles can cause autonecrosis when transiently expressed in tobacco (Chakrabarti et al. 2009; Wulff et al. 2004a, 2009). By extrapolation, it was suggested that $R$ gene activation in hybrids might contribute to the maintenance of interspecific postzygotic hybridization barriers (Bomblies and Weigel 2007; Wulff et al. 2004a). In support of this hypothesis, a hybrid incompatibility gene in Arabidopsis was recently cloned and shown to encode an NBS-LRR disease resistance homolog (Bomblies et al. 2007).

\section{Concluding remarks.}

In this review, we have sought to put the research described in the companion papers by Chakrabarti and associates (2009) and Wulff and associates (2009) into the overall context of molecular interactions between tomato and $C$. fulvum and, ultimately, perhaps the broader context of interactions between plants and non-cell-wall-penetrating pathogens, which are best exemplified by the interaction between tomato and C. fulvum. The reader is also referred to two other recent reviews of the field; one by Stergiopoulos and de Wit (2009), which places the tomato-C. fulvum pathosystem into the broader context of interactions between plants and extracellular fungal pathogens, and the other by de Wit and associates (2009), which examines the tomato-C. fulvum pathosystem in great depth. Inevitably, there is some overlap with these reviews but, wherever possible, we have attempted to present new ideas, provoke thought, and stimulate new experiments. As a consequence, we have posed more questions than there are answers, but this highlights the scope for more exciting developments in apoplastic molecular plant-microbe interactions.

\section{LITERATURE CITED}

Bolton, M. D., van Esse, H. P., Vossen, J. H., de Jonge, R., Stergiopoulos, I., Stulemeijer, I. J. E., van den Berg, G. C. M., Borrás-Hidalgo, O., Dekker, H. L., de Koster, C. G., de Wit, P. J. G. M., Joosten, M. H. A. J., and Thomma, B. P. H. J. 2008. The novel Cladosporium fulvum lysin motif effector Ecp6 is a virulence factor with orthologues in other fungal species. Mol. Microbiol. 69:119-136.

Bomblies, K., and Weigel, D. 2007. Hybrid necrosis: Autoimmunity as a potential gene-flow barrier in plant species. Nat. Rev. Genet. 8:382-393.

Bomblies, K., Lempe, J., Epple, P., Warthmann, N., Lanz, C., Dangl, J. L., and Weigel, D. 2007. Autoimmune response as a mechanism for a Dobzhansky-Muller-type incompatibility syndrome in plants. PLoS Biol. 5:e236.

Caicedo, A. L., and Schaal, B. A. 2004. Heterogeneous evolutionary processes affect $R$ gene diversity in natural populations of Solanum pimpinellifolium. Proc. Natl. Acad. Sci. U.S.A. 101:17444-17449.

Chakrabarti, A., Panter, S. N., Harrison, K., Jones, J. D. G., and Jones, D. A. 2009. Regions of the Cf-9B disease resistance protein able to cause spontaneous necrosis in Nicotiana benthamiana lie within the region controlling pathogen recognition in tomato. Mol. Plant-Microbe Interact. 22:1214-1226

Crameri, A., Raillard, S., Bermudez, E., and Stemmer, W. P. C. 1998. DNA shuffling of a family of genes from diverse species accelerates directed evolution. Nature 391:288-291.
Dangl, J. L., and Jones, J. D. G. 2001. Plant pathogens and integrated defence responses to infection. Nature 411:826-833.

de Kock, M. J. D., Iskandar, H. M., Brandwagt, B. F., Laugé, R., de Wit, P. J. G. M., and Lindhout, P. 2004. Recognition of Cladosporium fulvum Ecp2 elicitor by non-host Nicotiana spp. is mediated by a single dominant gene that is not homologous to known $C f$-genes. Mol. Plant Pathol. 5:397-408.

de Kock, M. J. D., Brandwagt, B. F., Bonnema, G., de Wit, P. J. G. M., and Lindhout, P. 2005. The tomato Orion locus comprises a unique class of Her 9 genes. Mol. Breeding 15:409-422.

de Wit, P. J. G. M., Joosten, M. H. A. J., Thomma, B. P. H. J., and Stergiopoulos, I. 2009. Gene for gene models and beyond: The Cladosporium fulvum-tomato pathosystem. Pages 135-156 in: The Mycota V: Plant Relationships. 2nd ed. H. B. Deising, ed. Springer, Berlin.

Dickinson, M., Jones, D. A., and Jones, J. D. G. 1993. Close linkage between the $C f-2 / C f-5$ and $M i$ resistance loci in tomato. Mol. PlantMicrobe Interact. 6:341-347.

Dixon, M. S., Jones, D. A., Keddie, J. S., Thomas, C. M., Harrison, K., and Jones J. D. G. 1996. The tomato $C f$-2 disease resistance locus comprises two functional genes encoding leucine-rich repeat proteins. Cell 84:451-459.

Dixon, M. S., Hatzixanthis, K., Jones, D. A., Harrison, K., and Jones, J. D. G. 1998. The tomato $C f-5$ disease resistance gene and six homologs show pronounced allelic variation in leucine-rich repeat copy number. Plant Cell 10:1915-1925.

Dixon, M. S., Golstein, C., Thomas, C. M., van der Biezen. E. A., and Jones, J. D. G. 2000. Genetic complexity of pathogen perception by plants: The example of $\operatorname{Rcr} 3$, a tomato gene required specifically by $C f-2$. Proc. Natl. Acad. Sci. U.S.A. 97:8807-8814.

Fradin, E. F., Zhang, Z., Juarez Ayala, J. C., Castroverde, C. D. M., Nazar, R. N., Robb, J., Liu, C.-M., and Thomma, B. P. H. J. 2009. Genetic dissection of Verticillium wilt resistance mediated by tomato Ve1. Plant Physiol. 150:320-332.

Haanstra, J. P. W., Laugé, R., Meijer-Dekens, F., Bonnema, G., de Wit, P. J. G. M., and Lindhout, P. 1999. The $C f-E C P 2$ gene is linked to, but not part of, the $C f-4 / C f-9$ cluster on the short arm of chromosome 1 in tomato. Mol. Gen. Genet. 262:839-845.

Haanstra, J. P. W., Meijer-Dekens, F., Laugé, R., Seetanah, D. C., Joosten, M. H. A. J., de Wit, P. J. G. M., and Lindhout, P. 2000. Mapping strategy for resistance genes against Cladopsorium fulvum on the short arm of chromosome 1 of tomato: $C f-E C P 5$ near the $H c r 9$ Milky Way cluster. Theor. Appl. Genet. 101:661-668.

Hammond-Kosack, K. E., Tang, S., Harrison, K., and Jones, J. D. G. 1998. The tomato $C f-9$ disease resistance gene functions in tobacco and potato to confer responsiveness to the fungal avirulence gene product Avr9. Plant Cell 10:1251-1266.

Hougenhout, S. A., van der Hoorn, R. A. L., Terauchi, R., and Kamoun, S. 2009. Emerging concepts in effector biology of plant associated organisms. Mol. Plant-Microbe Interact. 22:115-122.

Jones, D. A., Thomas, C. M., Hammond-Kosack, K. E., Balint-Kurti, P. J., and Jones, J. D. G. 1994. Isolation of the tomato $C f-9$ gene for resistance to Cladosporium fulvum by transposon tagging. Science 266:789793.

Joosten, M. H. A. J., Cozijnsen, T. J., and de Wit, P. J. G. M. 1994. Host resistance to a fungal tomato pathogen lost by a single base-pair change in an avirulence gene. Nature 367:384-386.

Joosten, M. H. A. J., Vogelsang, R., Cozijnsen, T. J., Verberne, M. C., and de Wit, P. J. G. M. 1997. The biotrophic fungus Cladosporium fulvum circumvents $C f-4$-mediated resistance by producing unstable AVR4 elicitors. Plant Cell 9:367-379.

Kobe, B., and Deisenhofer, J. 1995. A structral basis of the interactions between leucine-rich repeats and their protein ligands. Nature 374:183186.

Kooman-Gersmann, M. 1998. The AVR9 elicitor peptide of the tomato pathogen Cladopsorium fulvum: Molecular aspects of recognition. $\mathrm{PhD}$ Thesis, Wageningen University.

Kooman-Gersmann, M., Honée, G., Bonnema, G., and de Wit P. J. G. M. 1996. A high-affinity binding site for the AVR9 peptide elicitor of Cladosporium fulvum is present on plasma membranes of tomato and other solanaceous plants. Plant Cell 8:929-938.

Kooman-Gersmann, M., Vogelsang, R., Hoogendijk, E. C. M., and de Wit, P. J. G. M. 1997. Assignment of amino acid residues of the AVR9 peptide of Cladosporium fulvum that determine elicitor activity. Mol. PlantMicrobe Interact. 10:821-829.

Kooman-Gersmann, M., Vogelsang, R., Vossen, P., van den Hooven, H. W., Mahé, E., Honée, G., and de Wit, P. J. G. M. 1998. Correlation between binding affinity and necrosis-inducing activity of mutant AVR9 peptide elicitors. Plant Physiol. 117:609-618.

Krüger, J., Thomas, C. M., Golstein, C., Dixon, M. S., Smoker, M., Tang, S., Mulder, L., and Jones, J. D. G. 2002. A tomato cysteine protease re- 
quired for $C f$-2-dependent disease resistance and suppression of autonecrosis. Science 296:744-747.

Kruijt, M., Brandwagt, B. F., and de Wit, and P. J. G. M. 2004. Rearrangements in the $C f-9$ disease resistance gene cluster of wild tomato have resulted in three genes that mediate Avr9 responsiveness. Genetics 168:1655-1663.

Kruijt, M., Kip, D. J., Joosten, M. H. A. J., Brandwagt, B. F., and de Wit, P. J. G. M. 2005a. The $C f-4$ and $C f-9$ resistance genes against $C l a d o-$ sporium fulvum are conserved in wild tomato species. Mol. PlantMicrobe Interact. 18:1011-1021.

Kruijt, M., de Kock, M. J. D., and de Wit, P. J. G. M. 2005b. Receptor-like proteins involved in plant disease resistance. Mol. Plant Path. 6:85-97.

Kvitko, B. H., Park, D. H., Velásquez, A. C., Wei, C.-F., Russell, A. B., Martin, G. B., Schneider, D. J., and Collmer, A. 2009. Deletions in the repertoire of Pseudomonas syringae pv. tomato DC3000 Type III secretion effector genes reveal functional overlap among effectors. PLoS Pathog. 5:e1000388.

Laugé, R, Joosten, M. H. A. J., van den Ackerveken, G. F. J. M., van den Broek, H. W. J., and de Wit, P. J. G. M. 1997. The in planta-produced extracellular proteins ECP1 and ECP2 of Cladosporium fulvum are virulence factors. Mol. Plant-Microbe Interact. 10:725-734.

Laugé, R., Dmitriev, A. P., Joosten, M. H. A. J., and de Wit, P. J. G. M. 1998a. Additional resistance gene(s) against Cladosporium fulvum present on the $C f-9$ introgression segment are associated with strong PR protein accumulation. Mol. Plant-Microbe Interact. 11:301-308.

Laugé, R., Joosten, M. H. A. J., Haanstra, J. P. W., Goodwin, P. H., Lindhout, P., and de Wit, P. J. G. M. 1998b. Successful search for a resistance gene in tomato targeted against a virulence factor of a fungal pathogen. Proc. Natl. Acad. Sci. U.S.A. 95:9014-9018.

Laugé, R., Goodwin, P. H., de Wit, P. J. G. M., and Joosten, M. H. A. J. 2000. Specific HR-associated recognition of secreted proteins from Cladosporium fulvum occurs in both host and non-host plants. Plant J. 23:735-745.

Lindhout, P., Korta, W., Cislik, M., Vos, I., and Gerlagh, T. 1989. Further identification of races of Cladosporium fulvum (Fulvia fulva) on tomato originating from the Netherlands, France and Poland. Neth. J. Plant Path. 95:143-148.

Luderer, R., Rivas, S., Nürnberger, T., Mattei, B., van den Hooven, H. W., van der Hoorn, R. A. L., Romeis, T., Wehrfritz, J. M., Blume, B., Nennstiel, D., Zuidema, D., Vervoort, J., De Lorenzo, G., Jones, J. D. G., de Wit, P. J. G. M., and Joosten, M. H. A. J. 2001. No evidence for binding between resistance gene product $\mathrm{Cf}-9$ of tomato and avirulence gene product AVR9 of Cladosporium fulvum. Mol. Plant-Microbe Interact. 14:867-876

Luderer, R., Takken, F. L. W., de Wit, P. J. G., M., and Joosten, M. H. A. J. 2002. Cladosporium fulvum overcomes $C f$-2-mediated resistance by producing truncated AVR2 elicitor proteins. Mol. Microbiol. 45:875884

Padmanabhan, M., Cournoyer, P., and Dinesh-Kumar, S. P. 2009. The leucine-rich repeat domain in plant innate immunity: A wealth of possibilities. Cellular Microbiol. 11:191-198.

Panter, S. N., Hammond-Kosack, K. E., Harrison, K., Jones, J. D. G., and Jones, D. A. 2002. Developmental control of promoter activity is not responsible for mature onset of $C f-9 B$-mediated resistance to leaf mold in tomato. Mol. Plant-Microbe Interact. 15:1099-1107.

Parniske, M., and Jones, J. D. G. 1999. Recombination between diverged clusters of the tomato $C f-9$ plant disease resistance gene family. Proc. Natl. Acad. Sci. U.S.A. 96:5850-5855.

Parniske, M., Hammond-Kosack, K. E., Golstein, C., Thomas, C. M., Jones, D. A., Harrison, K., Wulff, B. B. H., and Jones, J. D. G. 1997. Novel disease resistance specificities result from sequence exchange between tandemly repeated genes at the $C f-4 / 9$ locus of tomato. Cell 91:821-832.

Parniske, M., Wulff, B. B. H., Bonnema, G., Thomas, C. M., Jones, D. A., and Jones, J. D. G. 1999. Homologues of the $C f-9$ disease resistance gene $(\mathrm{Hcr} 9 \mathrm{~s})$ are present at multiple loci on the short arm of tomato chromosome 1. Mol. Plant-Microbe Interact. 12:93-102.

Rivas, S., and Thomas, C. M. 2005. Molecular interactions between tomato and the leaf mold pathogen Cladosporium fulvum. Ann. Rev. Phytopathol. 43:395-436.

Rooney, H. C. E., van't Klooster, J. W., van der Hoorn, R. A. L., Joosten, M. H. A. J., Jones, J. D. G., and de Wit, P. J. G. M. 2005. Cladosporium Avr2 inhibits tomato Rcr3 protease required for Cf-2-dependent disease resistance. Science 308:1783-1786 (Erratum: Science 310:54).

Seear, P. J., and Dixon, M. S. 2003. Variable leucine-rich repeats of tomato disease resistance genes $C f-2$ and $C f-5$ determine specificity. Mol. Plant Pathol. 4:199-202.

Shabab, M., Shindo, T., Gu, C., Kaschani. F., Pansuriya. T., Chintha, R., Harzen, A., Colby, T., Kamoun, S., and van der Hoorn, R. A. L. 2008. Fungal effector protein AVR2 targets diversifying defense-related cys proteases of tomato. Plant Cell 20:1169-1183.

Song, J., Win, J., Tian, M., Schornack, S., Kaschani, F., Ilyas, M., van der Hoorn, R. A. L., and Kamoun, S. 2009. Apoplastic effectors secreted by two unrelated eukaryotic plant pathogens target the tomato defense protease Rcr3. Proc. Natl. Acad. Sci. U.S.A. 106:1654-1659.

Soumpourou, E., Iakovidis, M., Chartrain, L., Lyall, V., and Thomas, C. M. 2007. The Solanum pimpinellifolium $C f-E C P 1$ and $C f-E C P 4$ genes for resistance to Cladosporium fulvum are located at the Milky Way locus on the short arm of chromosome 1. Theor. Appl. Genet. 115:1127-1136.

Stemmer, W. P. C. 1994. Rapid evolution of a protein in vitro by DNA shuffling. Nature 370:389-391.

Stergiopoulos, I., and de Wit, P. J. G. M. 2009. Fungal effector proteins. Ann. Rev. Phytopathol. 47:233-263.

Stergiopoulos, I., Groenewald, M., Staats, M., Lindhout, P., Crous, P. W., and de Wit, P. J. G. M. 2007a. Mating-type genes and the genetic structure of a world-wide collection of the tomato pathogen Cladosporium fulvum. Fungal Genet. Biol. 44:415-429.

Stergiopoulos, I., de Kock, M. J. D., Lindhout, P., and de Wit, P. J. G. M. $2007 \mathrm{~b}$. Allelic variation in the effector genes of the tomato pathogen Cladosporium fulvum reveals different modes of adaptive evolution. Mol. Plant-Microbe Interact. 20:1271-1283.

Stevens, M. A., and Rick, C. M. 1988. Genetics and breeding. Pages 35109 in: The Tomato Crop, J. G. Atherton and J. Rudich, eds. Chapman and Hall, London.

Takken, F. L., Thomas, C. M., Joosten, M. H. A. J., Golstein, C., Westerink, N., Hille, J., Nijkamp, H. J., de Wit, P. J. G. M., and Jones, J. D. G. 1999. A second gene at the tomato $C f-4$ locus confers resistance to Cladosporium fulvum through recognition of a novel avirulence determinant. Plant J. 20:279-288.

Thomas, C. M., Jones, D. A., Parniske, M., Harrison, K., Balint-Kurti, P. J., Hatzixanthis, K., and Jones, J. D. G. 1997. Characterization of the tomato $C f-4$ gene for resistance to Cladosporium fulvum identifies sequences that determine recognitional specificity in $C f-4$ and $C f-9$. Plant Cell 9, 2209-2224.

Thomas, C. M., Tang, S., Hammond-Kosack, K., and Jones, J. D. G. 2000. Comparison of the hypersensitive response induced by the tomato $C f-4$ and $C f-9$ genes in Nicotiana spp. Mol. Plant-Microbe Interact. 13:465469.

Tian, M., Win, J., Song, J., van der Hoorn, R., van der Knaap, E., and Kamoun, S. 2007. A Phytophthora infestans cystatin-like protein targets a novel tomato papain-like apoplastic protease. Plant Physiol. 143:364-377.

van den Ackerveken, G. F. J. M., van Kan, J. A. L., and de Wit, P. J. G. M. 1992. Molecular analysis of the avirulence gene $a v r 9$ of the fungal tomato pathogen Cladosporium fulvum fully supports the gene-for-gene hypothesis. Plant J. 2:359-366.

van den Ackerveken, G. F. J. M, van Kan, J. A. L., Joosten, M. H. A. J., Muisers, J. M., Verbakel, H. M., and de Wit, P. J. G. M. 1993. Characterization of two putative pathogenicity genes of the fungal tomato pathogen Cladosporium fulvum. Mol. Plant-Microbe Interact. 6:210215.

van den Burg, H. A., de Wit, P. J. G. M., and Vervoort, J. 2001. Efficient ${ }^{13} \mathrm{C} /{ }^{15} \mathrm{~N}$ double labeling of the avirulence protein AVR4 in a methanolutilizing strain $\left(\mathrm{Mut}^{+}\right)$of Pichia pastoris. J. Biomol. NMR 20:251-261.

van den Burg, H. A., Westerink, N., Francoijs, K.-J., Roth, R., Woestenenk, E., Boeren, S., de Wit, P. J. G. M., Joosten, M. H. A. J., and Vervoort, J. 2003. Natural disulfide bond-disrupted mutants of AVR4 of the tomato pathogen Cladosporium fulvum are sensitive to proteolysis, circumvent $C f$-4-mediated resistance, but retain their chitin binding ability. J. Biol. Chem. 278:27340-27346.

van den Burg, H. A., Spronk, C. A. E. M., Boeren, S., Kennedy, M. A. Vissers, J. P. C., Vuister, G. W., de Wit, P. J. G. M., and Vervoort, J. 2004. Binding of the AVR4 elicitor of Cladosporium fulvum to chitotriose units is facilitated by positive allosteric protein-protein interactions: The chitin-binding site of AVR4 represents a novel binding site on the folding scaffold shared between the invertebrate and the plant chitin-binding domain. J. Biol. Chem. 279:16786-16796.

van den Burg, H. A., Harrison, S. J., Joosten, M. H. A. J., Vervoort J, and de Wit, P. J. G. M. 2006. Cladosporium fulvum Avr4 protects fungal cell walls against hydrolysis by plant chitinases accumulating during infection. Mol. Plant-Microbe Interact. 19:1420-1430.

van der Biezen, E. A., and Jones, J. D. G. 1998. Plant disease resistance proteins and the "gene-for-gene" concept. Trends Biochem. Sci. 23:454-456.

van der Hoorn, R. A. L. 2001. The Cf- 4 and Cf-9 proteins of tomato: Molecular aspects of specificity and elicitor perception. Ph.D. thesis, Wageningen University.

van der Hoorn, R. A. L., and Kamoun, S. 2008. From Guard to Decoy: A new model for perception of plant pathogen effectors. Plant Cell 20:2009-2017.

van der Hoorn, R. A. L., Laurent, F., Roth, R., and de Wit, P. J. G. M. 2000. Agroinfiltration is a versatile tool that facilitates comparative 
analyses of Avr $9 / C f$-9-induced and $A v r 4 / C f$-4-induced necrosis. Mol. Plant-Microbe Interact. 13:439-446.

van der Hoorn, R. A. L., Roth, R., and de Wit, P. J. G. M. 2001a. Identification of distinct specificity determinants in resistance protein Cf- 4 allows construction of a Cf-9 mutant that confers recognition of avirulence protein Avr4. Plant Cell 13:273-285.

van der Hoorn, R. A. L., Kruijt, M., Roth, R., Brandwagt, B. F., Joosten, M. H. A. J., and de Wit, P. J. G. M. 2001b. Intragenic recombination generated two distinct $C f$ genes that mediate AVR9 recognition in the natural population of Lycopersicon pimpinellifolium. Proc. Natl. Acad. Sci. U.S.A. 98:10493-10498.

van der Hoorn, R. A. L., Wulff, B. B. H., Rivas, S., Durrant, M. C., van der Ploeg, A., de Wit, P. J. G. M., and Jones, J. D. G. 2005. Structure-function analysis of Cf-9, a receptor-like protein with extracytoplasmic leucine-rich repeats. Plant Cell 17:1000-1015.

van Esse, H. P., Bolton, M. D., Stergiopoulos, I., de Wit, P. J. G. M., and Thomma, B. P. H. J. 2007. The chitin-binding Cladosporium fulvum effector protein Avr4 is a virulence factor. Mol. Plant-Microbe Interact. 20:1092-1101.

van Esse, H. P., van't Klooster, J. W., Bolton, M. D., Yadeta, K. A., van Baarlen, P., Boeren, S., Vervoort, J., de Wit, P. J. G. M., and Thomma B. P. H. J. 2008. The Cladosporium fulvum virulence protein Avr2 inhibits host proteases required for basal defense. Plant Cell 20:1948-1963.

Vervoort, J., van den Hooven, H. W., Berg, A., Vossen, P., Vogelsang, R., Joosten, M. H. A. J., and de Wit, P. J. G. M. 1997. The race-specific elicitor AVR9 of the tomato pathogen Cladosporium fulvum: A cystine knot protein. Sequence-specific ${ }^{1} \mathrm{H}$ NMR assignments, secondary structure and global fold of the protein. FEBS (Fed. Eur. Biochem. Soc.) Lett. 404:153-158.
Westerink, N. 2003. The role of AVR4 and AVR4E proteins in virulence and avirulence of the tomato pathogen Cladosporium fulvum: Molecular aspects of disease susceptibility and resistance. Ph.D. Thesis, Wageningen University.

Westerink, N., Brandwagt, B. F., de Wit, P. J. G. M., and Joosten, M. H. A. J. 2004. Cladosporium fulvum circumvents the second functional resistance gene homologue at the $C f-4$ locus $(H c r 9-4 E)$ by secretion of a stable avr4E isoform. Mol. Microbiol. 54:533-545.

Wubben, J. P., Joosten, M. H. A. J., and de Wit, P. J. G. M. 1994. Expression and localization of two in planta induced extracellular proteins of the fungal tomato pathogen Cladosporium fulvum. Mol. Plant-Microbe Interact. 7:516-524.

Wulff, B. B. H., Thomas, C. M., Smoker, M., Grant, M., and Jones, J. D. G. 2001. Domain swapping and gene shuffling identify sequences required for induction of an Avr-dependent hypersensitive response by the tomato $\mathrm{Cf}-4$ and $\mathrm{Cf}-9$ proteins. Plant Cell 13:255-272.

Wulff, B. B. H., Kruijt, M., Collins, P. L., Thomas, C. M., Ludwig, A. A., de Wit, P. J. G. M., and Jones, J. D. G. 2004a. Gene shuffling-generated and natural variants of the tomato resistance gene $C f-9$ exhibit different auto-necrosis-inducing activities in Nicotiana species. Plant J. 40:942956.

Wulff, B. B. H., Thomas, C. M., Parniske, M., and Jones, J. D. G. 2004b. Genetic variation at the tomato $C f-4 / C f-9$ locus induced by EMS mutagenesis and intralocus recombination. Genetics 167:459-470.

Wulff, B. B. H., Heese, A., Tomlinson-Buhot, L., Jones, D. A., de la Peña, M., and Jones, J. D. G. 2009. The major specificity-determining amino acids of the tomato $\mathrm{Cf}-9$ disease resistance protein are at hypervariable solvent-exposed positions in the central leucine-rich repeats. Mol. Plant-Microbe Interact. 22:1203-1213. 